\title{
A REVIEW \\ Biofertilizers - A noble technology for sustainable agriculture
}

\author{
Lukalapu Ravi Sankar, Lalichetti Sagar, B. Praveen and Saurav Barman \\ Department of Plant Pathology, Centurion University of Technology and Management, Parlakhemundhi (Odisha) \\ India \\ Email : bpyadav59@rediffmail.com
}

Article Info : Received : 05.01.2018; Accepted : 30.03 .2018

\begin{abstract}
Green revolution played a major role in reducing food crisis by introducing and developing high yielding varieties (HYV). Since, these varieties are highly fertilizer responsive, the usage of fertilizers increased to maximum extent with an aim to get higher productivity. Indiscriminate use of chemical fertilizers, pesticides and other highly productive systems had a serious effect on our environment. To attain sustainable production from soil reduced use of chemical fertilizers by substituting it with some new technologies is highly required. The bio fertilizer is one such technology which is gaining importance in integrated plant nutrient system as it maintains soil health, substitutes the chemical fertilizers thereby reducing their usage, increases microbial population of soil and minimizes environmental pollution.
\end{abstract}

Key words : Biofertilizers, Chemical fertilizers, Environmental pollution, High yielding varieties, Mass production

How to cite this paper : Sankar, Lukalapu Ravi, Sagar, Lalichetti, Praveen, B. and Barman, Saurav (2018). Biofertilizers - A noble technology for sustainable agriculture. Asian J. Bio. Sci., 13 (1) : 50-53.DOI : 10.15740/HAS/AJBS/13.1/50-53. 